Original Paper http://ajol.info/index.php/ijbcs http://indexmedicus.afro.who.int

\title{
Sub-acute evaluation of artesunate, amodiaquine and their combination on muscular coordination and morphology of the cerebellum of Wistar rats
}

\author{
AbdulGafar N. POPOOLA and Innocent O. IMOSEMI* \\ Department of Anatomy, College of Medicine, University of Ibadan, Nigeria. \\ *Corresponding author; E-mail: innosemi@yahoo.co.uk; Tel: +234-7068025958.
}

\begin{abstract}
Artemisinin Combination Therapy (ACT) is currently the best choice for the treatment of malaria. Artesunate-amodiaquine combination is one of the most commonly used ACTs in Nigeria with a very potent efficacy but not without side effects involving motor coordination. Currently, there is dearth of information on its sub-acute effect on the cerebellum. This study investigated the sub-acute effects of artesunate (AS), amodiaquine $(\mathrm{AQ})$ and artesunate + amodiaquine combination (AS+AQ) on the motor coordination, oxidative markers and morphology of the cerebellum of adult Wistar rats. Forty adult male Wistar rats were randomly divided into 4 groups, $\mathrm{n}=10$. The rats were administered orally for 3 days, distilled water (control, CT), 4 $\mathrm{mg} / \mathrm{kg}$ body weight AS, $10 \mathrm{mg} / \mathrm{kg}$ body weight AQ and $4 \mathrm{mg} / \mathrm{kg}$ AS $+10 \mathrm{mg} / \mathrm{kg}$ AQ. Rats were weighed, assessed for motor coordination and sacrificed on day 15. Brain tissues were excised and some cerebella preserved for oxidative stress and antioxidants while others were fixed in 10\% NBF for histological and immunohistochemical studies. Results showed significant decreased body weight of the AQ group compared to the CT; decreased time of fore limb grip in the AS and AQ groups compared with the CT. Test groups showed increased LPO and NO, and lower levels of SOD, CAT and GSH compared with the control. Artesunate and AQ had significantly reduced number of Purkinje cells, AQ and AS caused increased astrocyte population and increased expression of iNOS. Sub-acute studies of Wistar rats treated with artesunate, amodiaquine and their combination induced oxidative stress, reduced their motor function and impaired morphology of the cerebellum.
\end{abstract}

(C) 2020 International Formulae Group. All rights reserved.

Keywords: Artesunate, amodiaquine, behaviour, cerebellum, histology, immunohistochemistry.

\section{INTRODUCTION}

The use of artesunate (AS) and amodiaquine (AQ) as a form of artemisinin combination therapy (ASAQ), especially in the treatment of malaria infection has gained a wide acceptance among the people where the disease is epidemic. Furthermore, the efficacy of ASAQ as a chemotherapeutic regimen, especially for malaria has been well established by researchers. Although the effectiveness of artesunate and amodiaquine in their separate and combined (ACT) forms against malaria parasites is not questionable, the drugs also have history of toxicity and side effects (Toovey and Jamieson, 2004; Schmuck et al., 2009). Ekong et al. (2009) reported that artesunate may not be exhibit harmful effect at its recommended dose and may not affect behaviour. Inspite of the effectiveness of artemisinin derivatives 
treatment therapy for malaria; it has a number of side effects. Some clinical studies opined that it is well tolerated, and has a wide safety margin (Thuma et al., 2000; Hutagalung et al., 2006), whilst some other studies reported a number of neurological symptoms such as coma to auditory impairments (Toovey and Jamieson, 2004) and motor effects (Panossian et al., 2006) to its use. Animal studies reported that artemisinin and its derivatives induced neurotoxic and deadly effects in adults or embryos regardless of the specie used (mouse, rat, dog, non-human primate) (Clark et al., 2004; Schmuck et al., 2009). Amodiaquine caused lipid peroxidation and induced agranulocytosis and these processes had earlier been reported to result in agitation, aggressiveness, confusion, personality changes and psychotic symptoms in chronic doses and involuntary movements when acute dosages are consumed (Farombi, 2000). Ekong et al. (2009) reported that AQ+AS at their normal doses caused histological alterations in the cerebellum such as shrinkage of the Purkinje cells after 3 days administration; shrinkage of the Purkinje cell layer and cells as well as loss of the Purkinje cells after 6 days administration; while a double normal dose of $\mathrm{AQ}+\mathrm{AS}$ for 3 days caused shrinkage of the Purkinje cell layer and cells as well as loss of Purkinje cells. This study investigated the separate and combined sub-acute (after 14 days) effects of artesunate and amodiaquine on the body weight, biochemical markers of oxidative stress, muscular coordination, cytoarchitecture and immunohistochemisry of the cerebellum of adult Wistar rats.

\section{MATERIALS AND METHODS Animals and drugs}

Forty (40) Adult Male Wistar rats (Rattus norvegicus) weighing between 110 and $200 \mathrm{~g}$ procured from the animal house of the Department of Veterinary Physiology were used for this experiment. The experimental animals were handled and used in accordance with the guidelines provided by the University of Ibadan Animal Care and Use
Research

Ethics

Committee (UI-ACUREC), with reference nu mber UI-ACUREC/App/10/2016/002. They were kept in standard laboratory conditions under 24 hours light condition at room temperature of $25^{\circ} \mathrm{C}$. The animals were made to have access to feed and water ad-libitum throughout the period of the experiment. Tablets of Artesunate and Amodiaquine were procured from Diadem pharmacy, Ojoo Area, Ibadan (manufactured by ADAMS Pharmaceutical Co., Ltd., Anhui, China).

\section{Experimental design}

The forty adult male Wistar rats were randomly divided into four groups, $(n=10)$ as follows:

Group A - Distilled water and served as the control group (CT)

Group B - Artesunate (AS) (4 mg/kg body weight)

Group C - Amodiaquine (AQ) $(10 \mathrm{mg} / \mathrm{kg}$ body weight)

Group D - AS (4mg/kg body weight + AQ (10 $\mathrm{mg} / \mathrm{kg}$ body weight).

These doses represent the standard therapeutic doses of the AS and AQ and mimics a situation in which the ACT is used without any malaria infection (Adebayo et al., 2011). Drugs were administered orally with the use of oral gavage once per day between 8:00 am and 10:00 am for three days.

\section{Gross morphometry \\ Body weight}

As an index of physical status of the animals, the weight of each animal was monitored over the period of the study. The animals were weighed fortnightly with Electronic Weighing balance (Model: RS 225, Range: 0 to 600 $\mathrm{g}$, Make: Citizen) and the initial and final weights were used to determine weight difference. The formula below was used to calculate the percentage weight difference.

$\%$ Weight difference $=$ Final weight - Initial weight X100

Initial Weight 


\section{Neurobehavioural study}

\section{Motor function test (Forelimb grip strength)}

This was carried out on day 14 and each animal was exposed to four trials. The results were thereafter averaged and recorded. It tests for the muscular strength of the animals, which is a function of cerebellum and to assess the effect of drugs and toxins on muscle tone and neurodegeneration (Pichon et al., 2014). The forelimb paws of the rat were placed on a horizontally suspended metal wire (measuring $2 \mathrm{~mm}$ in diameter and $1 \mathrm{~m}$ in length), one meter above a landing area filled with soft bedding. The length of the time each rat was able to suspend before falling off the wire was recorded. A maximum time of 2 minutes was given to each rat after which it was removed.

\section{Biochemical assays for oxidative stress and antioxidants}

A measured part $(0.1 \mathrm{~g})$ from each cerebellar tissue was homogenized in $0.4 \mathrm{ml}$ of 5\% sucrose solution for enzyme study, after which it was centrifuged for 10 minutes at $3000 \mathrm{rpm}$. The supernatant gotten from the cerebellar tissues were kept frozen in the freezer at $4{ }^{\circ} \mathrm{C}$. The supernatant was later used for lipid peroxidation (LPO), superoxide dismutase (SOD), catalase (CAT), glutathione (GSH) and nitric oxide (NO) analyses.

\section{Histological and immunohistochemical studies}

The rats were sacrificed by quick cervical dislocations and the brain removed from the cranial cavity. The cerebellum was dissected out and fixed in $10 \%$ neutral buffered formalin (NBF). The cerebellar tissues were then processed employing routine paraffin wax embedding technique and stained with haematoxylin and eosine (H\&E) for cerebellar cytoarchitecture.

Immunohistochemical techniques were employed as follows;

I- Glial Fibrillary Acid Protein (GFAP) staining method described by Delcambre et al. (2016) to demonstrate the expression of astrocytes in the cerebellum.

II- Inducible nitric oxide synthase (iNOS) staining method for oxidative stress as described by Delcambre et al. (2016).

Images were captured from the cerebellar cortex with a 500-pixel Leica binocular microscope. Purkinje cell count, astrocytes population and the level of oxidative stress were quantified using the software, image-j.

\section{Statistical analysis}

Data collected was further analysed by one-way analysis of variance (ANOVA) followed by Tukey Post-hoc for multiple comparison using the GraphPad prism (San Diego, California, USA) version 7.02 at $\mathrm{p}<0.05$ and results presented as mean \pm SEM.

\section{RESULTS}

\section{Weight results}

There was increase in the body weight of the control (CT), AS and AS+AQ groups compared with the AQ group at $\mathrm{p}<0.05$ (Table $1)$.

\section{Neurobehavioural assessment}

The significantly decreased drop off time was seen in the AS and AQ groups compared with the $\mathrm{CT}$ at $\mathrm{p}<0.05$ (Table 2).

\section{Oxidative stress markers and antioxidants}

There was significantly increased lipid peroxidation, LPO (high Malondialdehyde, MDA level) and nitric oxide, NO, and decreased superoxide dismutase activity, SOD, catalase activity, CAT and reduced glutathione, GSH activity in the AS, AQ and $\mathrm{AS}+\mathrm{AQ}$ groups compared with the control at $\mathrm{p}<0.05$ (Table 3).

\section{Histological studies}

A decreased number of Purkinje cells was observed in the AS and AQ separate groups compared with the $\mathrm{CT}$ group and the $\mathrm{AS}+\mathrm{AQ}$ group at $\mathrm{p}<0.05$ (Figures 1 and 2). 


\section{Immunohistochemical studies}

Immunohistochemical showed significant increase in GFAP expression for astrocytes in the AS and AQ groups compared with the $\mathrm{CT}$ and $\mathrm{AS}+\mathrm{AQ}$ groups at $\mathrm{p}<0.05$. There was however no significant difference in GFAP expression between the AS+AQ and the $\mathrm{CT}$ groups at $\mathrm{p}>0.05$ (Figures 3 and 4 ).

A significantly higher immunoexpression of iNOS was seen in the AS, AQ and AS+AQ groups compared with the $\mathrm{CT}$ at $\mathrm{p}<0.05$ (Figures 5 and 6).

Table 1: Body weight of the animals following sub-acute study.

\begin{tabular}{lcccc}
\hline Groups & $\begin{array}{c}\text { Initial body } \\
\text { weight }(\mathbf{g})\end{array}$ & $\begin{array}{c}\text { Final body } \\
\text { weight }(\mathbf{g})\end{array}$ & $\begin{array}{c}\text { Weight } \\
\text { difference }(\mathbf{g})\end{array}$ & $\begin{array}{c}\text { \% weight } \\
\text { difference (g) }\end{array}$ \\
\hline $\mathrm{CT}$ & $110.00 \pm 3.06$ & $149.60 \pm 6.09$ & $39.60 \pm 5.38$ & 36.00 \\
\hline $\mathrm{AS}$ & $168.00 \pm 2.15$ & $176.00 \pm 11.23$ & $8.00 \pm 9.28^{*}$ & 4.50 \\
\hline $\mathrm{AQ}$ & $180.00 \pm 3.27$ & $125.30 \pm 8.48$ & $-54.70 \pm 8.32 * *$ & -30.40 \\
\hline $\mathrm{AS}+\mathrm{AQ}$ & $138.00 \pm 2.16$ & $156.60 \pm 6.12$ & $18.60 \pm 6.53$ & 13.50 \\
\hline $\begin{array}{l}\text { Values are expressed } \\
\text { Artesunate+Amodiaquine, } * \mathrm{p}<0.05 \text { vs control, } * * \mathrm{p}<0.01 \text { vs control. }\end{array}$ & & &
\end{tabular}

Table 2: Forelimb grip strength test in seconds following sub-acute study.

\begin{tabular}{lccccc}
\hline Group & CT & AS & AQ & AS+AQ \\
\hline Forearm Grip (secs) & $17.86 \pm 1.22$ & $8.00 \pm 1.11^{* *}$ & $7.43 \pm 0.92^{* *}$ & $15.43 \pm 1.17$ \\
\hline $\begin{array}{l}\text { Values are expressed as } \\
\text { Artesunate+Amodiaquine,. } * * \text { Mean } \pm \text { SEM, }<0.01 \text { vs control. }\end{array}$ & & &
\end{tabular}

Table 3: Oxidative stress markers antioxidants following sub-acute study.

\begin{tabular}{lrccc}
\hline Group & \multicolumn{1}{c}{ CT } & AS & AQ & AS+AQ \\
\hline LPO $(\mathrm{nmmol} / \mathrm{g})$ & $180.33 \pm 0.47$ & $233.07 \pm 2.26^{*}$ & $257.14 \pm 2.06^{*}$ & $223.32 \pm 1.99^{*}$ \\
NO $(\mu \mathrm{m} / \mathrm{mg})$ & $455.49 \pm 3.93$ & $472.32 \pm 0.91$ & $525.74 \pm 10.11^{*}$ & $480.95 \pm 2.92^{*}$ \\
SOD $(\mathrm{U} / \mathrm{mg})$ & $9.89 \pm 0.10$ & $5.70 \pm 0.16^{*}$ & $7.20 \pm 0.11^{*}$ & $7.54 \pm 0.13^{*}$ \\
CAT $(\mu \mathrm{m} / \mathrm{min} / \mathrm{mg})$ & $105.55 \pm 1.18$ & $69.59 \pm 1.54^{*}$ & $76.60 \pm 1.80^{*}$ & $65.01 \pm 1.07^{*}$ \\
GSH $(\mathrm{U} / \mathrm{L})$ & $11.15 \pm 0.32$ & $7.16 \pm 0.09^{*}$ & $5.80 \pm 0.15^{*}$ & $7.08 \pm 0.25^{*}$ \\
\hline
\end{tabular}

Values are expressed as Mean \pm SEM, $(n=5)$. CT-Control, AS- Artesunate, AQ-Amodiaquine, AS+AQ-Artesunate+Amodiaquine, ${ }^{*} \mathrm{p}<0.05$ vs control. 

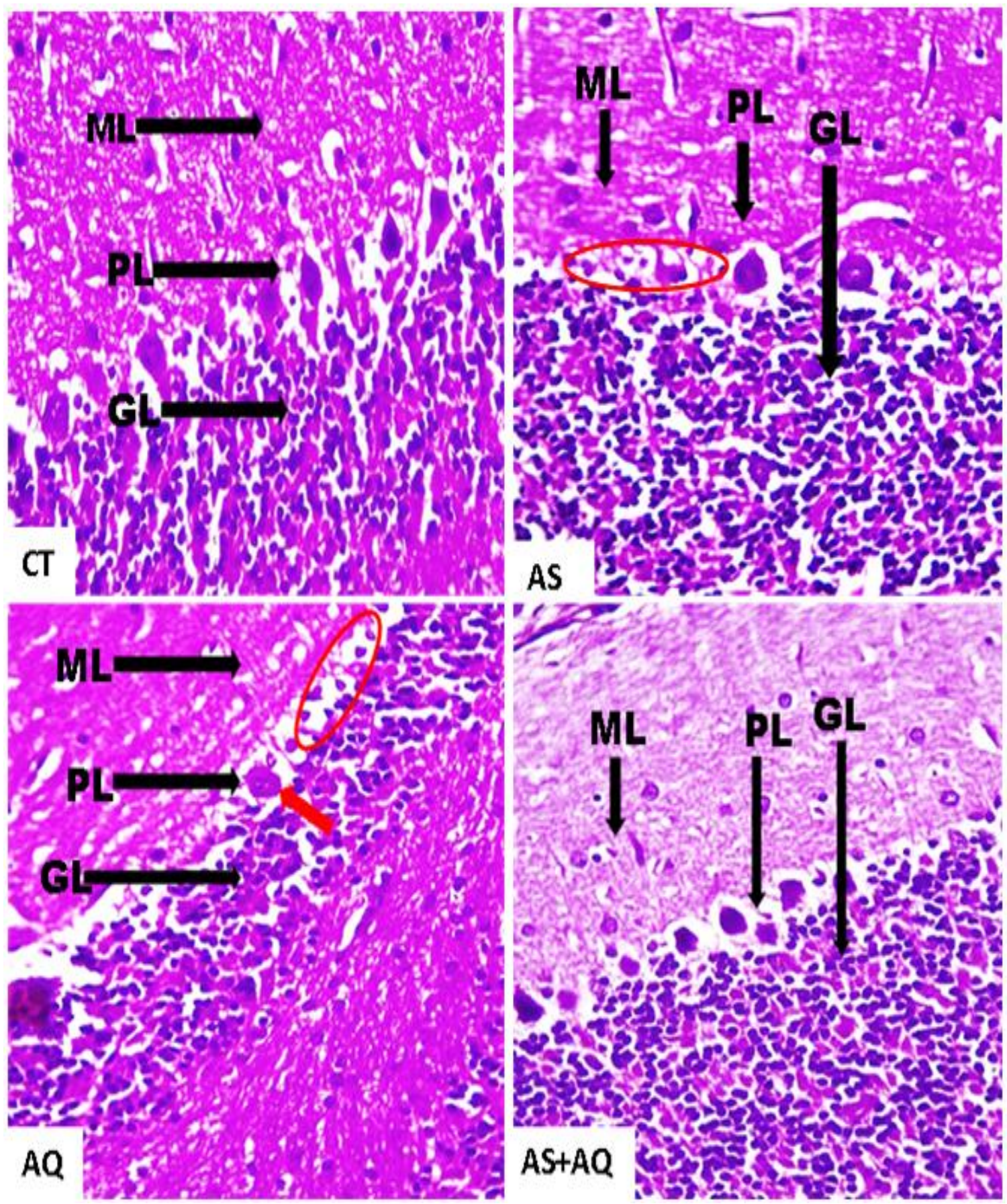

Figure 1: Section of the Cerebellar cortex of the Wistar rats following sub-acute study.

$\mathrm{H} \& \mathrm{E}(\mathrm{X} 400) . \mathrm{CT}=$ control, $\mathrm{AS}=$ artesunate, $\mathrm{AQ}=$ amodiaquine, $\mathrm{AS}+\mathrm{AQ}=$ artesunate + amodiaquine. The red arrow and red circles showed pyknotic and depleted Purkinje cells in the AS and AQ groups. ML- Molecular layer, PL = Purkinje layer and $\mathrm{GL}=$ Granular cell layer. 


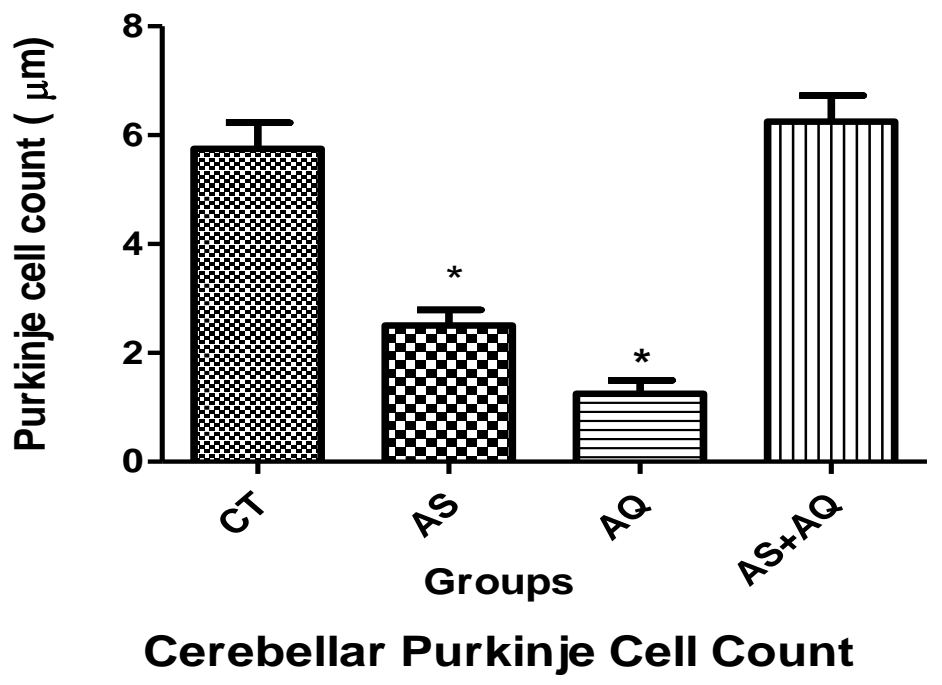

Figure 2: Cerebellar Purkinje Cell Count following sub-acute study. Means \pm S.E.M $(n=5)$. CTControl, AS-Artesunate, AQ- Amodiaquine, AS+AQ- Artesunate+Amodiaquine, ${ }^{*} \mathrm{p}<0.05$ vs control.

There were significantly lesser population of Purkinje cells in the AS and AQ separate groups compared with the CT and AS+AQ groups as observed in figures 1 and 2.

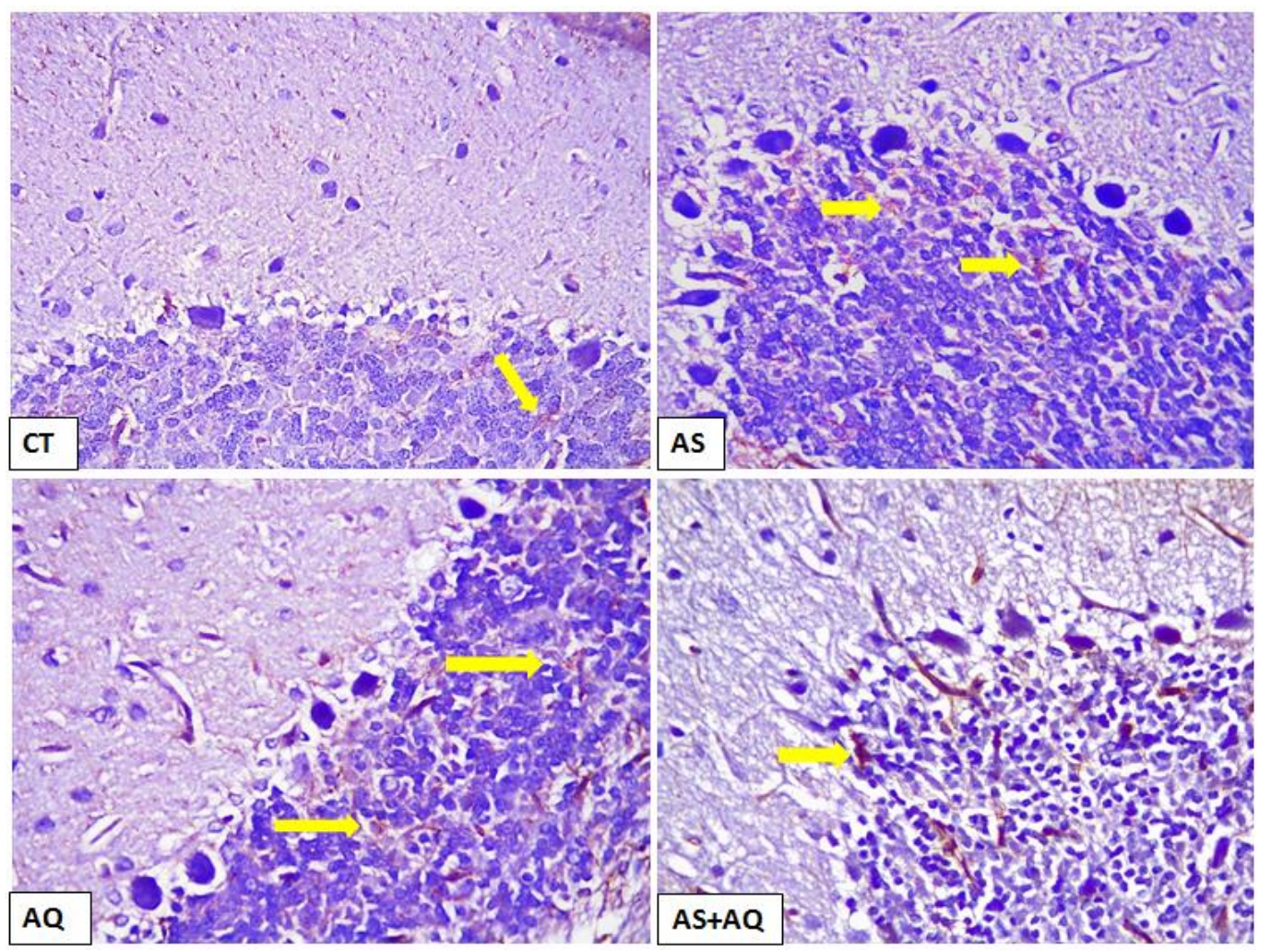

Figure 3: Immunoexpression of GFAP in the cerebellum of Wistar rats following sub-acute treatment with $\mathrm{AS}, \mathrm{AQ}$ and $\mathrm{AS}+\mathrm{AQ}$. GFAP $(\mathrm{X} 400)$. $\mathrm{CT}=$ control group, $\mathrm{AS}=$ artesunate group, $\mathrm{AQ}=$ amodiaquine group, $\mathrm{AS}+\mathrm{AQ}=$ artesunate-amodiaquine combination group. Yellow arrows= astrocytes. 


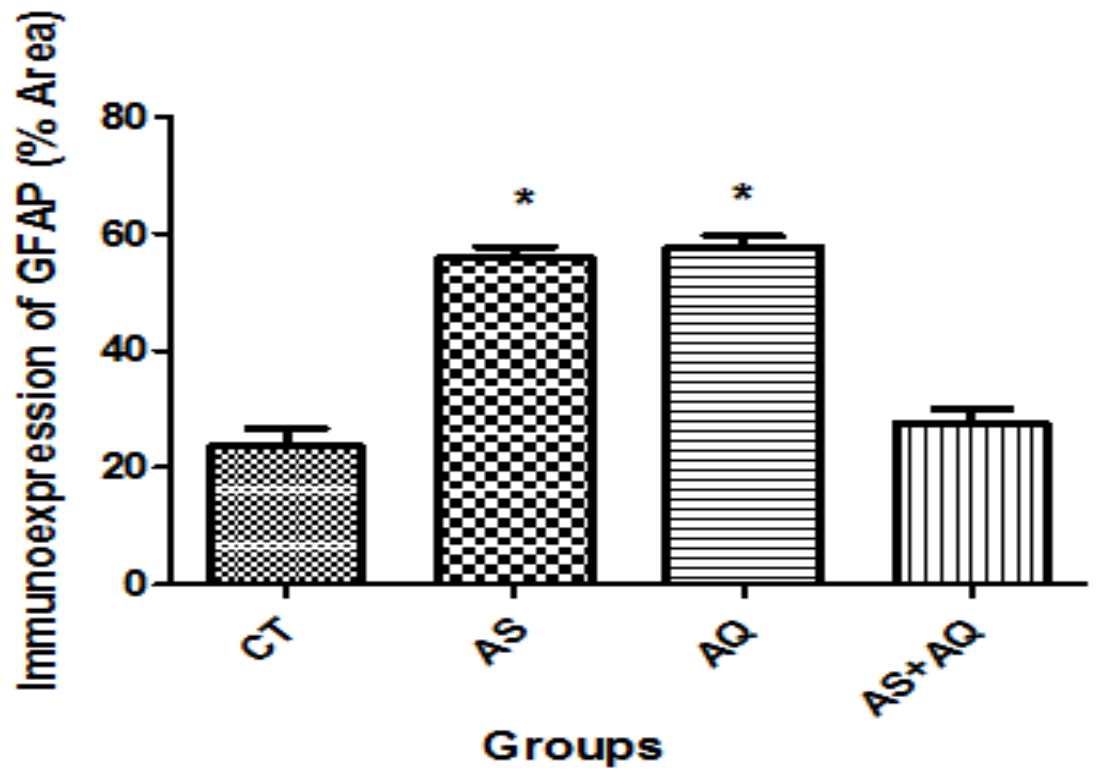

Figure 4: Immunoexpression of GFAP for astrocytes in the Cerebellum following sub-acute treatment with AS, AQ and AS+AQ. Mean \pm S.E.M $(n=5)$. CT- Control, AS- Artesunate, AQ- Amodiaquine, AS+AQArtesunate+Amodiaquine, ${ }^{*}<0.05$ vs $\mathrm{CT}$ and $\mathrm{AS}+\mathrm{AO}$ groups.

There were significant expression of GFAP in the AS and AQ groups compared with the CT and AS+AQ groups (Figures 3 and 4).
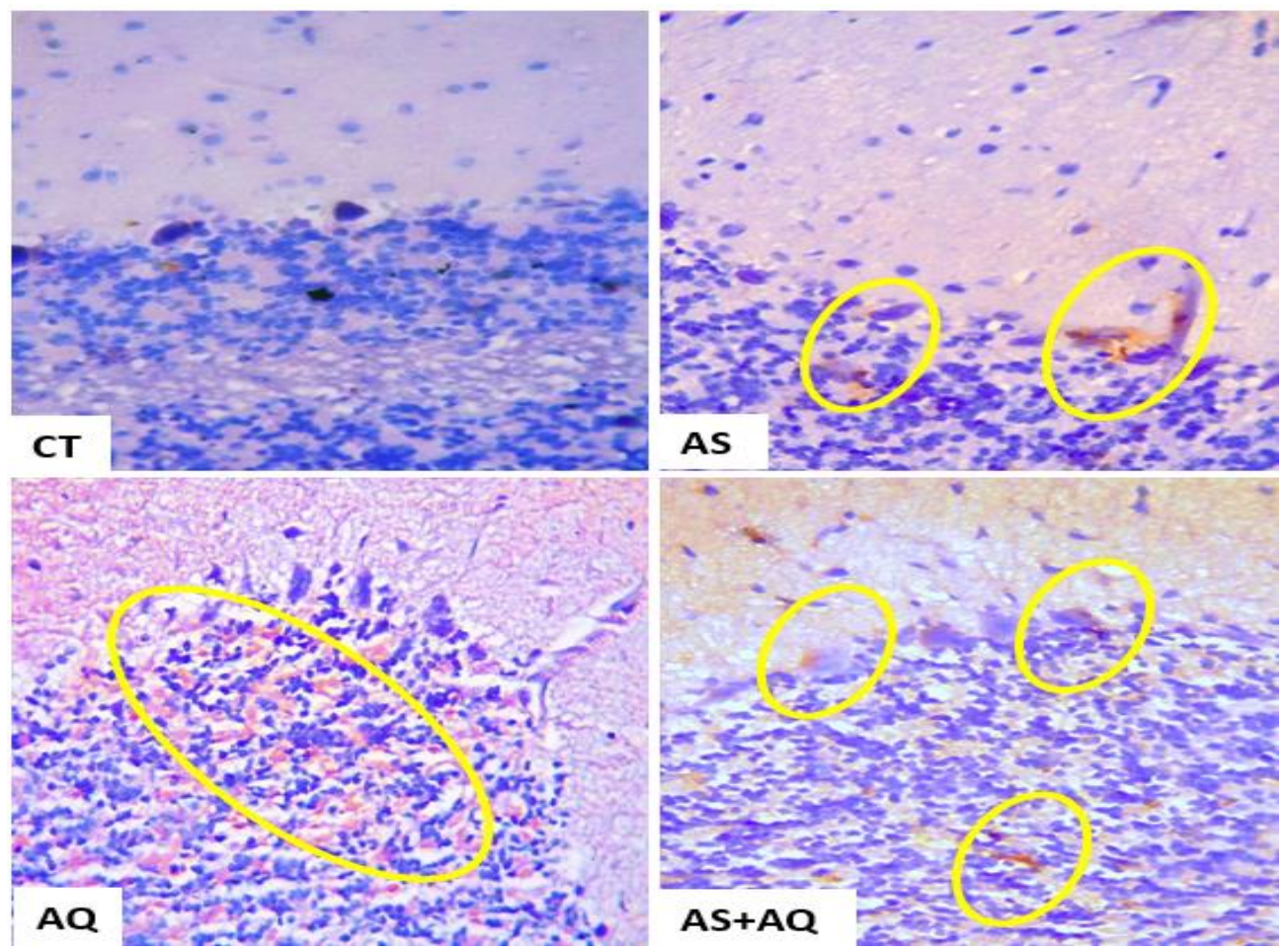

Figure 5: Section of Cerebellum of the Wistar rats following sub-acute treatment. iNOS (X400). CT= control group, $\mathrm{AS}=$ artesunate group, $\mathrm{AQ}=$ amodiaquine group, $\mathrm{AS}+\mathrm{AQ}=$ artesunate-amodiaquine combination group. Yellow rings show expression of iNOS. 


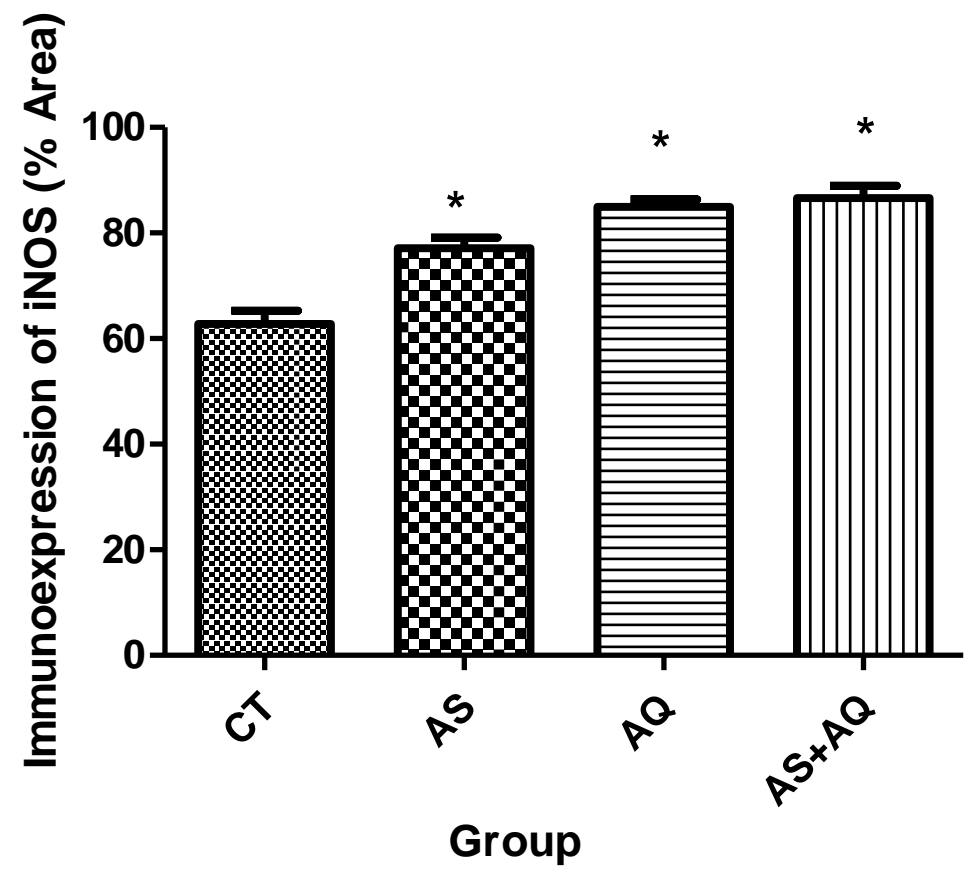

Figure 6: Immunoexpression of iNOS by the Cerebellum following sub-acute treatment. Means \pm S.E.M $(n=5)$. CT- Control, AS- Artesunate, AQ- Amodiaquine, AS+AQ- Artesunate +Amodiaquine, $* \mathrm{p}<0.05$ vs control.

A significantly higher immunoexpression of iNOS was seen in the AS, AQ and AS+AQ groups compared with the CT (Figures 5 and 6).

\section{DISCUSSION}

The sub-acute evaluation of artesunate (AS), amodiaquine (AQ) and artesunate + amodiaquine combination (AS+AQ) on the motor coordination, oxidative stress and morphology of the cerebellum of adult Wistar rats was studied. In this study, the weight loss observed in the AQ group (Table 1) may be associated with decreased consumption of food by the rats probably as a result of loss of appetite and low nutrient uptake following treatment with the drug. This is in consonance with the findings of Udolom et al. (2015) who reported that there was decline in feeding rate of their experimental animals administered with amodiaquine and cifloxacine combination. Blundell et al. (2017) in their study opined that drug that causes reduction in weight may have acted on the appetite control centre of the hypothalamus in the brain to reduce feelings of hunger. On the other hand, the AS+AQ groups showed an increase in body weight change not significantly different from that of the CT group. This finding suggests that the combination form of the drugs (AS+AQ) neither reduced their appetite for food nor negatively affect the feeding pattern of the animals. Furthermore, the higher body weight difference seen in the combined group may also suggest that the combination regimen of these two drugs is better than the monotherapy of the individual drug in terms of weight sustenance. This finding compares favourably with the finding of Utoh-Nedosa et al. (2009) who reported increase in the mean body weight of rats administered artemisinin. It also agrees with Olumide et al. (2011) who reported significant increase in body and relative organ weights of rats administered with artesunate and that of Izunya et al. (2010) who also reported that artesunate at its normal and double normal 
doses had no effect on the body weights of rats. The similarities in these studies may be hinged on the similarity in dosages used.

The result of the fore-limb grip test shows that artesunate and amodiaquine separate groups significantly lowered grip strength than the animals in the control and combination groups (Table 2). This could be an indication that AS and AQ administered separately caused muscle weakness in the animals as seen in the reduced activities observed with the animals after few minutes of receiving the drugs. This result is consistent with the report of pfizer (2016) that the use of amodiaquine within the therapeutic dose caused lethargy (weakness or inactivity characterized by lack of energy). However, the combined administration of the drugs showed improved grip strength in the rats similar to that of the control.

The increased lipid peroxidation indicated by an increased malondialdehyde (MDA) levels in the cerebellar tissue, observed in the AS, AQ and AS+AQ groups compared to the CT group (Table 3) strongly suggests that the drugs, separately or combined triggered the production of MDA, a by-product of lipid peroxidation. The high level of MDA in the $\mathrm{AQ}, \mathrm{AS}$ and $\mathrm{AS}+\mathrm{AQ}$ groups suggests the generation of free radicals such as hydrogen peroxide, nitric oxide and superoxide anions. This oxidative damage was more in the AQ and AS groups than in the AS+AQ. This indicates that the combination therapy may be better in managing lipid peroxidation process and reducing toxic stress to the brain cells than the individual drugs. Earlier reports have shown that $\mathrm{AQ}$, in its mechanism of action against malaria parasite, binds to nucleoproteins of the parasites and hinders its DNA and RNA polymerases (Ekong et al., 2009). It also triggers free radicals in the form of amodiaquine-quinine-immine and semi quinine-immine which triggers lipid peroxidation (Obianime and Aprioku, 2009) which have been reported to cause damage to tissue in vivo (Mayes, 2000). Lipid helps to replace worn-out membranes and serve as electrical insulators thereby allowing rapid propagation of depolarization waves along myelinated nerve (Mayes, 2000). Disruption of this function may result in neurodegeneration, which may lead to defective functioning of the brain (Singh, 2013). The level of nitric oxide (NO) was significantly higher in AQ group than the CT, AS and AS+AQ groups (Table 3), an indication that AQ generated free radicals which have also migrated to the brain. Nitric oxide is a marker for inflammatory changes in the brain. It is a major secretory product of mammalian cells that initiates host defense, homeostatic and development functions by either direct effect or intercellular signaling (Gibananada and Hussain, 2002). The significant increase in the level of NO in the cerebellar tissue of AQ group indicates inflammatory responses in the brain tissues of the rats.

The level of cerebellar tissue superoxide dismutase (SOD) and catalase (CAT) was found to be significantly lower in the AS, AQ and AS+AQ groups than the CT group (Table 3). The SOD and CAT are antioxidant enzymes which act as free radical scavenger that arrest oxidative stress (Gibananada and Hussain, 2002). The low levels of SOD and CAT in the AS, AQ and $\mathrm{AS}+\mathrm{AQ}$ groups is a strong indication that the drugs generated high level of free radicals in the brain tissues of the experimental animals leading to the low level of SOD and CAT in those groups compared with the $\mathrm{CT}$ group which may have resulted from the overwhelming activity of the free radicals.

The level of reduced glutathione (GSH) was significantly lower in AS, AQ and AS+AQ groups than the CT group (Table 3). In cells, glutathione is maintained in the reduced form by the enzyme glutathione reductase and in turn reduces other metabolites and enzyme systems, such as ascorbate in the glutathione-ascorbate cycle, 
glutathione peroxidases and glutaredoxins, as well as reacting directly with oxidants (Gibananada and Hussain, 2002). Due to its high concentration and its central role in maintaining the cell's redox state, glutathione is one of the most important cellular antioxidants (Gibananada and Hussain, 2002). It is also a marker of oxidative stress due to its antioxidant properties. These three biochemicals (SOD, CAT and GSH) are agents of defense against oxidative stress. Therefore, the low level glutathione in the experimental groups (Table 3 ) is an indication of its extinction as a result of its mopping activities over the free radicals generated. Gibananada and Hussain (2002) reported that oxidative stress, results from an imbalance between reactive oxygen species (ROS) or reactive nitrogen species (RNS) and antioxidant defense of the body. Oxidative damage is one result of such an imbalance and includes oxidative modification of cellular macromolecules, induction of cell death by apoptosis or necrosis, as well as structural tissue damage (Nair et al., 2008).

The significant decrease in the number of Purkinje cells of the cerebellum in the AS and most especially AQ separate groups (Figures 1 and 2) suggest that the two drugs caused significant loss of Purkinje cells through induced cell death (necrosis). Further evidences through physical observation also revealed that AQ caused karyolysis of Purkinje cells (Figure 1). The decreased Purkinje cell density and observed karyolysis may be a complication of the lipid peroxidation and oxidative stress seen in this study (Table 3), as lipid peroxidation had been reported to be responsible for damage to tissue in vivo shortly after cell membrane disruption (Mayes, 2000). Karyolysis of the Purkinje cells may reduce the output signals emanating from the cerebellar cortex to other parts of the brain and alter body functions; this is because the Purkinje fibres are the major cortical output of the cerebellum. Consequently, cerebellar dysfunction may occur resulting in some motor deficit like gait disturbances, convulsion and dizziness (Ekong et al., 2009). Loss of Purkinje cells might also cause loss of motor coordination and may culminate into death (Stucki et al., 2016), hence, the reduced activity and lesser grip strength seen in the experimental rats (Table 2). The high expression of GFAP in both the AS and AQ groups (Figures 3 and 4) is an indication of increased population of astrocytes in the cerebellum of these groups of animals which suggests neuronal damage in those animals. Astrocytes play many important roles in glutamate and potassium uptake, production of growth factors, cytokines and extracellular matrix proteins, in both the healthy and injured central nervous system (Kettenmann and Ransom, 2004). They also play important roles in regulating neuronal excitability, for example, by controlling the extracellular concentrations of potassium, glutamate and adenosine (Tian et al., 2005). This finding aligns with an earlier study which reported astrogliosis as the early sign of neuronal loss (Kersaitis et al., 2004).

The cerebelli of the AS, AQ and AS+AQ groups had significantly higher expression of iNOS compared to the CT (Figures 5 and 6). This strongly suggests that the drugs generated free radicals including NO which has percolated into the brain tissues within the duration of the experiment. This further explains the oxidative stress seen in the biochemical analyses. Oxidative stress had earlier been implicated in tissue damage (Mayes, 2000) and defective function of the brain (Singh, 2013).

\section{Conclusion}

The sub-acute exposure of adult Wistar rats to artesunate (AS), amodiaquine (AQ) and their combination (AS+AQ) revealed that $\mathrm{AQ}$ at its normal therapeutic dose caused significant decrease in the body weights; AQ and AS decreased motor coordination; AS, AQ and AS+AQ induced oxidative stress; AS and AQ caused karyolysis and depletion of 
Purkinje cells, and astrogliosis in the rat cerebellum. The findings from this study may be an indication that artesunate and amodiaquine and their combination have some delayed sub-acute deleterious effects in the cerebellum of adult Wistar rat.

\section{COMPETING INTERESTS}

The authors declare that there are no competing interests in this study.

\section{AUTHORS' CONTRIBUTIONS}

The two authors conceived the idea of the study and designed the study. Author ANP wrote the protocol, conducted the experiment, researched the literature, wrote the first draft and did the statistical analysis. Author IOI corrected the first draft, made some technical inputs and came out with the final draft. Both authors read and approved the final draft.

\section{ACKNOWLEDGEMENTS}

We wish to acknowledge Professor E.O. Farombi, Head, Molecular Drug Metabolism and Toxicology Laboratory, Department of Biochemistry, University of Ibadan, Nigeria, for the utilization of his laboratory for this research.

\section{REFERENCES}

Adebayo JO, Igunnu A, Arise RO, Malomo SO. 2011. Effects of co-administration of artesunate and amodiaquine on some cardiovascular disease indices in rats. Elsevier Journal of Food and Chemical Toxicology, 49: 45-48. DOI: 10.1016/j.fct.2010.09.022

Agoma UP, Merimikwu MM, Ismaila MW, Omalu IT, Oguche VI, Odey S. 2008 Efficacy, Safety and Tolerability of Plasmodium Falciparum Malaria in four geographical zones of Nigeria. Malaria J., 7: 172-180. DOI: 10.1186/1475-28757-172\#Bib1

Aprioku JS, Obianime AW. 2011. Structure Activity - Relationship (SAR) of Artemisinin on some Biological Systems in male Guinea pigs. Insight Pharmaceutical Science, 1(1):1 - 10. DOI: 10.5567/IPHARMA-IK.2011.1.10

Blundell J, Finlayson G, Axelsen M, Flint A, Gibbons C, Kvist T, Hjerpsted JB. 2017. Effects of once-weekly semaglutide on appetite, energy intake, control of eating, food preference and body weight in subjects with obesity. Diabetes, Obesity and Metabolism, 19(9): 1242. DOI: $10.1111 /$ dom.12932

Broe M, Kril J, Hallidal GM. 2004. Astrocytic degeneration relates to the severity of disease in frontotemporal dementia. Brain, 127: 2214-2220. DOI: $10.3389 /$ fnagi.2016.00045

Clark RL, White TEK, Clode SA, Gaunt I, Winstanley P. Ward SA. 2004. Developmental Toxicity of Artesunate and an Artesunate Combination in the Rat and Rabbit, Birth Defects Research Part B. Developmental and Reproductive Toxicology, 71(6): 380-394. DOI: https://doi.org/10.1002/bdrb.20027

Ekong MB, Igiri AO, Egwu AO. 2009. Histomorphologic alterations of the cerebellum of Wistar rats following Amodiaquine plus Artesunate administration. Internet Journal of Medical Update, 4(2): 15-18. DOI: 10.4314/ijmu.v4i2.43838

Farombi EO, Tahnteng JG, Agboola O, Nwankwo JO, Emerole GO. 2000. Chemoprevention of 2-acetyl aminofluorene-induced hepatotoxicity and lipid peroxidation in rats by kolaviron-A Garcinia kola seed extract. Food Chem. Toxicol., 38 (6): 535-541. DOI: https://doi.org/10.1016/S02786915(00)00039-9

Gibananada R, Hussain SA. 2002. Oxidants, antioxidants and carcinogenesis. Ind. J. Exp. Biol., 40: 1213-1232.

Hutagalung R, Htoo $\mathrm{H}$, Nwee $\mathrm{P}$, Arunkamomkiri J, Zwang J, Carrara VI. 2006. A Case-Control Auditory Evaluation of Patients Treated with 
Artemether-Lumefantrine. The American Journal of Tropical Medicine and Hygiene, $\quad \mathbf{7 4}(2)$ : 211-214. DOI: 10.4269/ajtmh.2006.74.211

Izunya AM, Nwaopara AO, Oaikhena GA. 2010. Effect of chronic oral administration of chloroquine on the weight of the heart in Wistar rats. Asian $J \quad$ Med Sci., 2(3):127-31. DOI: http://154.68.224.61:8080/xmlui/handle/ $123456789 / 629$

Kersaitis C, Halliday GM, Kril JJ. 2004. Regional and cellular pathology in frontotemporal dementia: relationship to stage of disease in cases with and without Pick bodies. Acta Neuropathol., 108: 515-523. DOI: $10.1007 / \mathrm{s} 00401-$ 004-0917-0

Kettenmann H, Ransom BR. 2004. Neuroglia (2nd edn). Oxford University Press: Oxford, UK. DOI: https://doi.org/10.1046/j.14714159.1997.68062625.x

Mayes PA. 2000. Lipid of physiologic significance. In Harper's Biochemistry (25th edn), Murray RK, Granner DK, Mayes PA, Rodwell VW (eds). Mecurant-Hall: New York; 160-171.

Nair V, O'Neil CL, Wang PG. 2008. Malondialdehyde. In Encyclopedia of Reagents for Organic Synthesis. John Wiley \& Sons: New York. DOI: https://doi.org/10.1002/047084289X.rm0 13.pub2

Obianime AW, Aprioku JS. 2009. Comparative study of artesunate, ACTs and their combinants on the biochemical parameters of male guinea-pigs. Afr. $J$. Biotechnol., 8(19): 5059-5065. DOI: https://www.ajol.info/index.php/ajb/artic le/view/65215

Olumide SA, Raji Y. 2011. Long-term administration of artesunate induces reproductive toxicity in male rats. Journal of Reproductive and Infertility, 12(4): 49-65.
Panossian LA, Garga NI, Pelletier D. 2006. Toxic Brainstem Encephalopathy after Artemisinins Treatment for Breast Cancer. Annals of Neurology, 58(5): 812-813. DOI: 10.1002/ana.20620.

pfizer. $\quad$ Larimal $^{\circledR}$ Drug Leaflet.Ipca Laboratories Ltd. 48, Kandivi Ind. Estate, Mumba; 400067. 2016.

Pichon X, Wattiez A, Becamel C, Ehrlich I, Bockaert J, Eschalier A, Marin P, Courteix C. 2010. Disrupting 5-HT2A Receptor/PDZ Protein Interactions Reduces Hyperalgesia and Enhances SSRI Efficacy in Neuropathic Pain. Mol Ther., $\quad$ 18(8): $1462-1470$.

DOI: $10.1038 / \mathrm{mt} .2010 .101$

Schmuck G, Klaus AM, Krötlinge F. Langewische FW. 2009. Developmental and Reproductive Toxicity Studies on Artemisone, Birth Defects Research Part B. Developmental and Reproductive Toxicology, $\quad \mathbf{8 6}(2)$ : $\quad 131-143$. DOI: 10.1002/bdrb.20192

Sembulingam K, Sembulingam P. 2012. Essentials of Medical Physiology $\left(6^{\text {th }}\right.$ edn). Jaypee Brothers Medical Publishers (P) Ltd.: New Delhi.

Singh IN, Gilmer LK, Miller DM, Cebak JE, Wang JA, Hall ED. 2013. Phenelzine mitochondrial functional preservation and neuroprotection after traumatic brain injury related to scavenging of the lipid peroxidation-derived aldehyde 4hydroxy-2-nonenal. J Cereb Blood Flow Metab., 33: 593-599. DOI: 10.1038/jcbfm.2012.211

Stucki DM, Ruegsegger C, Steiner S, Radecke J, Murphy MP, Zuber B, Saxena S. 2016. Mitochondrial impairments contribute to Spinocerebellar ataxia type 1 progression and can be ameliorated by the mitochondria-targeted antioxidant MitoQ. Free Radic. Biol. Med., 97: 427440. DOI:

10.1016/j.freeradbiomed.2016.07.005.

Thuma PE, Bhat GJ, Mabeza GF, Osborne C, Biemba G, Shakankale GM. 2000. A 
Randomized Controlled Trial of Arte Motil (Beta-Arteether) in Zambian Children with Cerebral Malaria. The American Journal of Tropical Medicine and Hygiene, 62(4): 524-529. DOI: 10.4269/ajtmh.2000.62.524.

Tian GF, Azmi H, Takano T, Xu Q, Peng W, Lin J, Oberheim N, Lou N, Wang X, Zielke HR, Kang J, Nedergaard M. 2005. An astrocytic basis of epilepsy. Nat. Med., 11: $\quad$ 973-981. DOI: 10.1038/nm1277.

Toovey S, Jamieson A. 2004. "Response to: Artemisinin Derivatives: Toxic for Laboratory Animals, Safe for Humans?" Toxicology Letters, 151(3): 491-492. DOI: 10.1016/j.toxlet.2004.05.003

Ubulom PME, Udobi CE, Madu MI. 2015. Amodiaquine and Ciprofloxacin Combination in Plasmodiasis Therapy. Journal of Tropical Medicine, 2015:
2015.

DOI: https://doi.org/10.1155/2015/947390

Utoh-Nedusa PA, Akah PA, Okoye TC, Okoli CO. 2009. Evaluation of toxic effects of dihydroarteminisin on vital organs of Wistar albino rats. American Journal of Pharmacology and Toxicolog, 4(4): 169-179. DOI: 10.1002/ame2.12029

Verkhratsky A, Parpura V. 2015. Astrogliopathology in neurological, neurodevelopmental and psychiatric disorders. Neurobiol. Dis., 3: 1-8. DOI: 10.1016/j.nbd.2015.03.025

Verkhratsky A, Rodríguez JJ, Steardo L. 2014b. Astrogliopathology: a central element of neuropsychiatric diseases? Neuroscientist, 20: 576-588. DOI: $10.1177 / 1073858413510208$. 